\title{
Electrolyzed water as a sustainable cleaning and disinfection chemical for SMEs Malaysian meat processing food industries: Challenges and uncertainties
}

\author{
Nurul Izzah Khalida, Norashikin Ab Aziza,b, , Nurfatimah Mohd Thania, Ruzanna Shapi'ia, Nur Farhana Abd Rahmanª
}

${ }^{a}$ Department of Process and Food Engineering, Faculty of Engineering, Universiti Putra Malaysia, 43400 UPM Serdang, Selangor, Malaysia

${ }^{b}$ Halal Products Research Institute, University Putra Malaysia, 43300 UPM Serdang, Selangor, Malaysia

\section{ARTICLE HISTORY}

Received: 2 March 2020

Received in revised form: 9 March 2020

Accepted: 10 March 2020

Available Online: 12 March 2020

The cleaning and disinfection are also known as sanitation process and it is a prerequisite for most of food safety standards. Sanitation process is often neglected by industrialist due to it is a plant downtime and incurs cost. Limited resources and knowledge have prevented the implementation of effective cleaning and sanitation process in the Small and Medium-sized Enterprises (SMEs) food factories in Malaysia. The commercial food-grade chemical which is expensive can be a burden for SMEs food manufacturers. Hence some of the SMEs food manufacturers have opted for non-food grade cleaning chemicals (e.g., laundry detergent) to clean their food processing equipment and factory environment. The non-food grade chemical is less rinsible and can leave a fragrance. The application of this non-food grade chemical not only caused chemical contamination to food products but also on riverine. The improper disposal of wastewater sourcing from the Malaysian food industry is known to pose pollution problems and violate environmental regulation. The odourless and rinsible electrolyzed water (EW) is seen as a potential alternative for the commercial cleaning and sanitation detergents. Moreover, papers are claiming that there is no wastewater treatment are needed when the EW is used as the cleaning and disinfecting chemicals.

EW is known as a green cleaner and sanitizer due to its properties of being eco-friendly where it only uses diluted salt (e.g., sodium chloride, potassium chloride, and magnesium chloride) (Al-Haq et al., 2005). Two different types of electrolyzed water can be generated using the on-site electrolysis generator which equipped with 1) a membrane that allows ion exchange, 2) an anode electrode, and 3) a cathode electrode. Schematic of electrolyzed water generator and produced compounds is shown in Figure 1 (Huang et al., 2008). Reactions involve during electrolysis process is shown in Table 1 (Rahman et al., 2016). The acidic electrolyzed water (AcEW) and alkaline electrolyzed water (AlEW) are also known the electrolyzed oxidizing water and electrolyzed reduced water, respectively. The AcEW (pH less than 3 and oxidative-reduction potential (ORP) more than $1100 \mathrm{mV}$ ) is produced at the anode and AlEW ( $\mathrm{pH}$ more than 11 and ORP less than $-800 \mathrm{mV}$ ) is produced at the cathode. The AcEW was reported to possess good antimicrobial agent against many types of food borne pathogens (e.g., Escherichia coli, Salmonella, and Listeria monocytogenes), for different types of food and food-contact surfaces. Whereas AlEW are effective in removal of food residue, oil, fat, and grease from food processing surfaces such as cutting boards (Hsu, 2005), stainless steel (Dev et al., 2014; Walker et al., 2005; Wang et al., 2016), PVC hose, rubber (liners and gaskets), and plastic (polysulfone) (Walker et al., 2005).

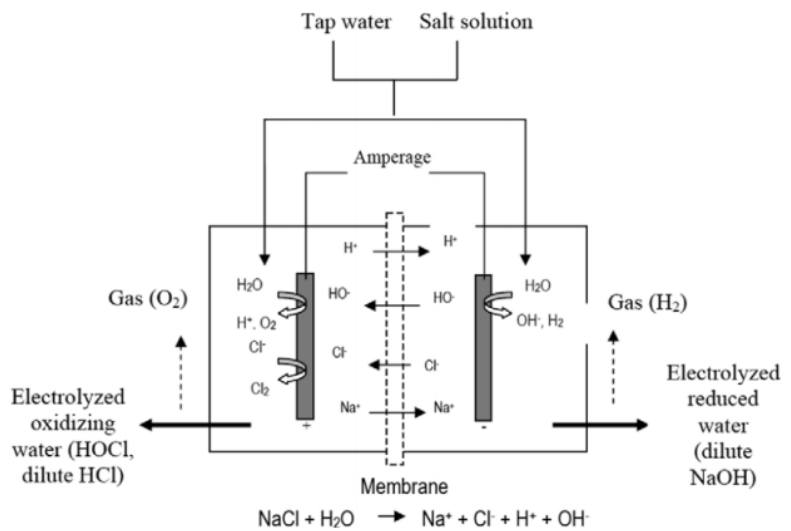

Figure 1. Schematic of electrolyzed water generator and produced compounds (Huang et al., 2008)

Nevertheless, there are still a lot of uncertainties in applying EW in the cleaning and disinfection of the meat processing factories. The effectiveness of using AlEW on removing the fat and grease, which is a crucial problem in the meat processing food industry has not been well-defined. Fabrizio and Cutter, (2004; 2005) have reported that AcEW alone, AlEW alone or combination treatment (AlEW followed by AcEW) is still not sufficient to reduce microbes, in order to meet with the regulatory requirements for control of Listeria monocytogenes on ready-to-eat (RTE) meats. The fat, oil, and grease have become invisible barrier which preventing the effectiveness of the AlEW, resulting in low performance of AlEW. Thus, innovative EW (formulate EW with a safe amount of cleaning agents) need to be studied to overcome the problem during cleaning and sanitation in the meat processing. Another drawbacks of EW are the short shelf life (the tendency to lose its antimicrobial properties), and the corrosiveness of AcEW and AlEW (due to extreme pH, free chlorine content or high ORP). However, since it can be produced on-site and on-demand, the shelf life of EW is not a major problem. SMEs factories with limited storage areas and has no intention to keep the unused EW in their storage area. However, a study needs to be carried out to investigate the corrosivity of EW on the surfaces of processing equipment.

In order to substitute the usage of hazardous cleaning chemicals, United States regulators have consented the application of EW in the industry. Meanwhile, in the European Union, EW can only be utilized in drinking water. However, due to the protein inactivation of EW, its application on food products are not permitted. The potential of EW for cleaning and sanitizing has not been given enough recognition in Malaysia. Furthermore, the prospects of EW have never been presented to 
Table 1. Reactions involved during electrolysis process (Rahman et al., 2016)

\begin{tabular}{l} 
Anode \\
\hline $2 \mathrm{NaCl}=\mathrm{Cl}_{2}(g)+2 e^{-}+2 \mathrm{Na}^{+}$ \\
$2 \mathrm{H}_{2} \mathrm{O}(\mathrm{l})=4 \mathrm{H}^{+}(\mathrm{aq})+\mathrm{O}_{2}(g)+4 e^{-}$ \\
$\mathrm{Cl}_{2}+\mathrm{H}_{2} \mathrm{O}(\mathrm{l})=\mathrm{HCl}+\mathrm{HOCl}$
\end{tabular}

Acidic electrolyzed water can be obtained at anode

$\mathrm{pH}<3$

ORP $>1100 \mathrm{mV}$

Available chlorine concentration of 10-90 ppm

The negatively charged ions $\left(\mathrm{OH}^{-}\right.$and $\left.\mathrm{Cl}^{-}\right)$move toward the anode where electrons are released. (Illustration shows in Figure 1)

Hypochlorous acid $(\mathrm{HOCl})$, hydrochloric acid $(\mathrm{HCl})$, oxygen gas $\left(\mathrm{O}_{2}\right)$, and chlorine gas $\left(\mathrm{Cl}_{2}\right)$ are generated.

Malaysia regulators. SMEs' food manufacturers will have uncertainties in using the EW.

As a conclusion, there are too many uncertainties in applying EW in Malaysia meat processing food industries. Extensive research needs to be done to find the innovative EW (formulate EW with a safe amount of cleaning agents); the impacts of EW on riverine of Malaysia; and Malaysian SMEs industrialist perception on effective cleaning and new cleaning technology. Hence, the future advancement in this area will benefit the SMEs meat processing industries greatly.

\section{References}

Al-Haq, M. I., Sugiyama, J., \& Isobe, S. (2005). Applications of Electrolyzed Water in Agriculture \& Food Industries. Food Science and Technology Research, 11(2), 135-150. https://doi.org/10.3136/fstr.11.135

Dev, S. R. S., Demirci, A., Graves, R. E., \& Puri, V. M. (2014). Optimization and modeling of an electrolyzed oxidizing water based Clean-In-Place technique for farm milking systems using a pilot-scale milking system. Journal of Food Engineering, 135, 1-10. https://doi.org/10.1016/j.jfoodeng.2014.02.019

Fabrizio, K. A., \& Cutter, C. N. (2004). Comparison of electrolyzed oxidizing water with other antimicrobial interventions to reduce pathogens on fresh pork. Meat Science, 68(3), 463-468. https://doi.org/10.1016/j.meatsci.2004.04.013

Fabrizio, K. A., \& Cutter, C. N. (2005). Application of electrolyzed oxidizing water to reduce Listeria monocytogenes on ready-to-eat meats. Meat Science, 71(2), 327-333. https://doi.org/10.1016/j.meatsci.2005.04.012

Hsu, S. Y. (2005). Effects of flow rate, temperature and salt concentration on chemical and physical properties of electrolyzed oxidizing water. Journal of Food Engineering, 66 , 171-176. https://doi.org/doi:10.1016/j.jfoodeng.2004.03.003

Huang, Y. R., Hung, Y. C., Hsu, S. Y., Huang, Y. W., \& Hwang, D. F. (2008). Application of electrolyzed water in the food industry. Food Control, 19, 329-345. https://doi.org/10.1016/j.foodcont.2007.08.012

Rahman, S., Khan, I., \& Oh, D. H. (2016). Electrolyzed Water as a Novel Sanitizer in the Food Industry: Current Trends and Future Perspectives. Comprehensive Reviews in Food Science and Food Safety, 15(3), 471-490. https://doi.org/10.1111/1541-4337.12200

Walker, S. P., Demirci, A., Graves, R. E., Spencer, S. B., \& Roberts, R. F. (2005). Response surface modelling for cleaning and

\section{Cathode}

$2 \mathrm{H}_{2} \mathrm{O}(l)+2 e^{-}=2 \mathrm{OH}^{-}(a q)+\mathrm{H}_{2}(g)$

$2 \mathrm{NaCl}+2 \mathrm{OH}^{-}=2 \mathrm{NaOH}+\mathrm{Cl}^{-}$

Alkaline electrolyzed water can be obtained at cathode

$\mathrm{pH}>11$

ORP $<-800 \mathrm{mV}$

The positively charged ions $\left(\mathrm{Na}^{+}\right.$and $\left.\mathrm{H}^{+}\right)$move toward the cathode where they gain electrons. (Illustration shows in Figure 1)

Sodium hydroxide $(\mathrm{NaOH})$ and hydrogen gas, $H_{2}$ is generated. disinfecting materials used in milking systems with electrolysed oxidizing water. International Journal of Dairy Technology, 58(2), 65-73. https://doi.org/10.1111/j.1471-0307.2005.00190.x

Wang, X., Puri, V. M., Demirci, A., \& Graves, R. E. (2016). Mathematical modeling and cycle time reduction of deposit removal from stainless steel pipeline during cleaning-in-place of milking system with electrolyzed oxidizing water. Journal of Food Engineering, 170, 144159. https://doi.org/10.1016/j.jfoodeng.2015.09.027 